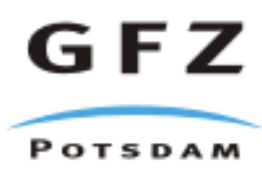

Originally published as:

Klemann, V., Wolf, D. (2007): Using Fuzzy Logic for the Analysis of Sea-level Indicators with Respect to Glacial-isostatic Adjustment: An Application to the Richmond-Gulf Region, Hudson Bay. - Pure and Applied Geophysics, 164, 4, 683-696,

DOI: 10.1007/s00024-007-0191-X. 


\section{Using fuzzy logic for the analysis of sea-level indicators with respect to glacial-isostatic adjustment: an application to the Richmond-Gulf region, Hudson Bay Volker Klemann*, Detlef Wolf}

GeoForschungsZentrum Potsdam, Sekt. 1.3, Gravity Field and Earth Models, Telegrafenberg, D-14473 Potsdam, Germany, (volkerkgfz-potsdam.de)

* corresponding author

Short title: Fuzzy logic in analysis of sea-level indicators

Key words: Canada, data analysis, fuzzy logic, glacial-isostatic adjustment, sea-level indicator, sea-level change

\footnotetext{
Abstract

An important constraint for the inference of mantle viscosity is the variation of the Holocene relative sea-level (RSL) height (with respect to today) following the last deglaciation. As a measure of this variation, sea-level indicators (SLIs) related to the RSL heights at specific past time epochs are used. For the inversion of the RSL-height change in terms of mantle viscosity, neighbouring SLIs may be grouped into an RSL diagram taken as representative for the region considered. Usually, the nominal height and age of a particular SLI are the only characteristics considered when determining the former RSL height. However, only SLIs based on isolation basins yield a narrow range for this height, whereas SLIs based on fossil samples provide a lower bound (shells), an upper bound (driftwood) or a finite interval (basal peat) for it. To use also fossil samples objectively, we develop a classification scheme of the depositional conditions based on fuzzy logic. After the definition of appropriate membership functions, this method leads to a systematic interpretation of the large number of SLIs available. We apply this method to SLIs from the Richmond-Gulf region, southeastern Hudson Bay, near the former glaciation center of Canada and derive a decay time of $5 \mathrm{ka}$ for the exponential function best fitting the RSL diagram for this region.
} 
Volker Klemann, Detlef Wolf
Fuzzy logic in analysis of sea-level indicators

Page: 2 of 28

\section{Introduction}

For our study, several concepts are required and must be defined. By sea-level indicator (SLI), we denote some fossil sample, such as shell, peat or driftwood, that is indicative, usually in an indirect way, of the position of the relative sea-level height (RSL) at the time of deposition. The age of an SLI is commonly determined by radiocarbon dating and its observational SLI height determined as the elevation relative to the present mean sea-level height. Commonly, neighbouring SLIs are combined to construct a sea-level diagram taken as representative of the average location of the SLIs considered. Implicit in this construction is that the observational RSL height agrees with the observational SLI height or is offset from it by a constant amount. Assuming that the glacialisostatic adjustment (GIA) process following the last deglaciation and the associated global rise of the sea-level height, governs the observational RSL height during the Holocene, such diagrams may then be used to infer the viscosity distribution in the earth's interior or the deglaciation history. Near the centers of the former ice sheets, the SLIs indicate that GIA has proceeded nearly exponentially in time after deglaciation. A useful quantity for further analysis is therefore the decay time of the exponential function that best fits the observational RSL heights.

The main problem of this procedure is the varied quality of the SLIs used. Usually, this problem is solved by arbitrarily excluding SLIs whose location seems to be anomalous in some way. Related to this is the question of which SLI types should be included or excluded when fitting the exponential function and determining the decay time. Thus, Lambeck et al. (1998) questioned comprehensive compilations comprising any type, such as that by Tushingham and Peltier (1993), and suggested to use as SLIs only basal peats or lake sediments indicative of marine-lacustrine transitions (isolation events). The disadvantage of this restrictive selection is that it excludes all coasts where the quality of SLIs is poor. Moreover, isolation events have been mapped extensively only in Europe.

An alternative solution to this problem is based on the use of fuzzy logic (e.g. Demicco and 
Klir, 2004). In the sense employed here, it encompasses a system of concepts, principles and methods for approximate, rather than exact, modes of reasoning (Novák \& Perfilieva, 2000 in Klir, 2004). Thus, instead of transforming the observational SLI height into an observational RSL height according to some standard scheme, we merely assume that the depositional conditions of the SLI type - where the fossil sample representing the SLI lived or settled - indicate some RSLheight range. In accordance with this, we suppose that the predicted RSL height indicates a height range, expressed by the fuzzy set appropriate to the particular SLI type considered, and take this into account when defining the misfit between observational SLI height and predicted RSL height.

Our study proceeds as follows. First, in presenting the methodology, we will define a fuzzy set, $\mathbf{P}_{i}$, for the prediction of the depositional condition of the SLI considered by combining the fuzzy set, $\mathbf{E}_{i}$, containing the information about the depositional condition of the SLI type with the predicted RSL height, $h_{i}^{\mathrm{P}}$. After this, we will define a fuzzy set, $\mathbf{O}_{i}$, for the observational SLI height, $h_{i}^{\mathrm{O}}$, where the statistics related to the errors of levelling and dating are taken into account. Based on these two fuzzy sets, we will calculate the fit, $\mathbf{F}_{i}$, by their intersection, and derive as a robust measure an algebraic number expressing the possibility, $p_{i}$, that the prediction fits the observation. As an example, our method will be employed to determine the decay time of GIA for the Richmond-Gulf region, southeastern Hudson Bay, using the SLI evidence of this region.

\section{Application of fuzzy logic}

Fuzzy logic is based on fuzzy sets allowing us to quantify the imprecision of a statement. For our application, this means that we replace the predicted RSL height, $h_{i}^{\mathrm{P}}$, associated with the $i$ th SLI by a fuzzy set representing the depostional condition of the sample:

$$
\begin{aligned}
\mathbf{P}_{i}: \quad X_{i}^{\mathrm{P}} & \rightarrow[0,1], \\
h & \rightarrow \mu_{i}^{\mathrm{P}}(h) .
\end{aligned}
$$


Here, the depositional condition is defined by the support, $X_{i}^{\mathrm{P}}$, of the fuzzy set (the height range where the SLI lived or settled) and by the membership function, $\mu_{i}^{\mathrm{P}}$, indicating the possibility, in the range $[0,1]$, that the species of the SLI lived or settled at the height, $h$, relative to the present mean sea-level height (Figure 1).

\subsection{Fuzzification}

The predicted RSL height, either based on the assumption of exponential decay - as studied here - or on a forward calculation for a particular earth-ice-model combination - as studied by Wolf et al. (2006) - is

$$
h_{i}^{\mathrm{P}}=m\left(\boldsymbol{x}_{i}, t_{i}\right), \quad \mathrm{SLI}_{i} \in \mathcal{S},
$$

where $m$ denotes the model used for prediction, $\boldsymbol{x}_{i}$ and $t_{i}$ the location and calibrated age, respectively, of the $i$ th SLI in the set, $\mathcal{S}$, considered and $h_{i}^{\mathrm{P}}$ its predicted RSL height. The latter is used to predict the depositional condition of the SLI relative to the present mean sea-level height as follows.

First, we define the depositional condition of the $i$ th SLI relative to the contemporaneous mean seal level by the fuzzy set

$$
\begin{aligned}
\mathbf{E}_{i}: \quad X_{i} & \rightarrow[0,1], \quad \operatorname{SLI}_{i} \in \mathcal{S}, \\
h & \rightarrow \mu_{i}^{\mathrm{E}},
\end{aligned}
$$

where $\mu_{i}^{\mathrm{E}}$ is the membership function describing the depositional condition and $X_{i}$ its support. The prediction of the depositional condition of the $i$ th SLI is then defined by the shift associated with the predicted RSL height:

$$
\begin{aligned}
\mathbf{P}_{i}:=\mathbf{E}_{i}+h_{i}^{\mathrm{P}}: \quad X_{i}^{\mathrm{P}}:=X_{i}+h_{i}^{\mathrm{P}} & \rightarrow[0,1] \\
h & \rightarrow \mu_{i}^{\mathrm{P}}(h):=\mu_{i}\left(h-h_{i}^{\mathrm{P}}\right) .
\end{aligned}
$$


To consider the errors of the observational SLI height, $h_{i}^{\mathrm{O}}$, we define a fuzzy set based on their statistics. We assume here that the measurements are normally distributed with the probabilitydensity function

$$
n\left(h, h_{i}^{\mathrm{O}}, \sigma_{i}^{2}\right)=\frac{1}{\sqrt{2 \pi} \sigma} \exp \left[-\frac{\left(h-h_{i}^{\mathrm{O}}\right)^{2}}{2 \sigma_{i}^{2}}\right] .
$$

The standard deviation in height, $\sigma_{i}$, is calculated from the height error, $\Delta h_{i}$, and the error in dating and its calibration, $\Delta t_{i}$ :

$$
\sigma_{i}=\sqrt{\Delta h_{i}^{2}+\left(\left.\frac{d h^{\mathrm{P}}}{d t}\right|_{\left(x_{i}, t_{i}\right)} \Delta t_{i}\right)^{2}},
$$

where the contribution due to the error in the location of the SLI has been neglected. Instead of using probabilities, we will, in the following, employ possibilities. Based on the possibilityprobability principle (Zadeh, 1978) stating that the degree of possibility of an event is at least equal to its degree of probability, we define the fuzzy set for the observational SLI height, $h_{i}^{\mathrm{O}}$, with the probability-density function given by Eq. 5 according to Civanlar and Trussell (1986) as

$$
\begin{array}{r}
\mathbf{O}_{i}: \quad(-\infty, \infty) \rightarrow[0,1], \\
h \rightarrow \mu_{i}^{\mathrm{O}}:= \begin{cases}1 & \text { if }\left|\frac{h-h_{i}^{\mathrm{O}}}{\sigma_{i}}\right|<a, \\
\exp \frac{a^{2}}{2} \exp \left[-\frac{\left(h-h_{i}^{\mathrm{O}}\right)^{2}}{2 \sigma_{i}^{2}}\right] & \text { otherwise },\end{cases}
\end{array}
$$

where $\mu_{i}^{\mathrm{O}}$ is the membership function of the observational height and the support is infinite. The parameter $a$ is related to the confidence level, which is $\sim 90 \%$ if we assume that $a=1$.

As the next step, we define the fuzzy set representing the fit to the observation associated with the $i$ th SLI achieved by the modelling as the standard intersection (Klir, 2004):

$$
\begin{aligned}
\mathbf{F}_{i}:=\mathbf{P}_{i} \cap \mathbf{O}_{i}: \quad X_{i}^{\mathrm{P}} & \rightarrow[0,1], \\
h & \rightarrow \mu_{i}^{\mathrm{F}}:=\min \left\{\mu_{i}^{\mathrm{P}}(h), \mu_{i}^{\mathrm{O}}(h)\right\},
\end{aligned}
$$

where $\mu_{i}^{\mathrm{F}}$ is the respective membership function and its support is equal to $X_{i}^{\mathrm{P}}$ because $X_{i}^{\mathrm{F}}=$ $(-\infty, \infty) \cap X_{i}^{\mathrm{P}}=X_{i}^{\mathrm{P}}$ holds. 


\subsection{Defuzzification}

For the appraisal of the modelling, we derive from the fuzzy set, $\mathbf{F}_{i}$, of the fit the possibility

$$
p_{i}:=\sup _{h \in X_{i}^{\mathrm{P}}} \mu_{i}^{\mathrm{F}}(h)
$$

that the prediction represents the observation. In particular, $p_{i}=1$ means that the model fits the data. A further quantity of interest is the revised nominal height, $h_{i}^{\mathrm{F}}$, of the SLI defined as the height where $p_{i}$ holds and the difference from $h_{i}^{\mathrm{O}}$ has a minimum:

$$
h_{i}^{\mathrm{F}}=\min _{\mu_{i}^{\mathrm{F}}(h)=p_{i}}\left|h-h_{i}^{\mathrm{O}}\right| .
$$

Figure 2, top, shows the possibility, $p_{i}$, calculated from Eq. 9 for variable observational SLI Figure 2 height, $h_{i}^{\mathrm{O}}$, constant standard deviation, $\sigma_{i}=1$, and trapezoidal membership function, $\mu_{i}^{\mathrm{P}}$, of the prediction with a core $\left(\mu_{i}^{\mathrm{P}}=1\right)$ in the range $h \in[4,8]$ and ramps on both sides with widths of 1 . For $h_{i}^{\mathrm{O}}=2, \mu_{i}^{\mathrm{O}}, \mu_{i}^{\mathrm{P}}$ and their intersection, $\mu_{i}^{\mathrm{F}}$, are shown in Figure 2, bottom. Also plotted are $h_{i}^{\mathrm{F}}$ and $h_{i}^{\mathrm{O}}$. The figure shows that $p_{i}=1$ inside the core of $\mu_{i}^{\mathrm{P}}$ extended by the standard error of the measurement and that $p_{i}$ decays with distance from it.

In the following, we define the misfit of a set of SLIs by

$$
\chi:=\frac{1}{N} \sum_{i=1}^{N}\left(1-p_{i}\right), \quad \operatorname{SLI}_{i} \in \mathcal{S},
$$

where $N$ is the total number of SLIs considered.

\subsection{Definition of membership functions for SLIs}

Art Dyke (pers. comm.) suggested to distinguish three classes of SLIs. The first class, where the observational SLI height, $h_{i}^{\mathrm{O}}$, defines an upper bound for the former mean sea-level height, mainly consists of marine species, such as shells found in their living position. The second class, where $h_{i}^{\mathrm{O}}$ defines a lower bound for the former mean sea-level height, mainly consists of terrestrial species, such as tree roots. The third class, where $h_{i}^{\mathrm{O}}$ defines a finite range for the former mean 
sea-level height, comprises isolation events, basal peats and coastal regions where, in addition to samples of the first class, the highest former mean sea-level height (marine limit) is known. Here, we refine this classification and consider the particular depositional conditions of SLI. This means that the tidal range, the probable height of storm beaches, the support of the depositional condition, or the probability that material usually washed to the shore sank can be recovered from supplementary information associated with the SLIs considered.

The advantage of using fuzzy logic is that such refinements can be quantified by combining the corresponding fuzzy sets. Thus, for a shallow water shell able to live also in the tidal range, we obtain

$$
\mathbf{E}^{\mathrm{SW}}=\mathbf{E}^{\mathrm{SW}} \cup \mathbf{E}^{\mathrm{MTR}}
$$

as the union of the fuzzy set describing a shallow-water habitat, $\mathbf{E}^{\mathrm{SW}}$, and the fuzzy set describing the mean tidal range, $\mathbf{E}^{\mathrm{MTR}}$, for this region (Figure 3). For simplicity, we assume the membership functions to be of trapezoidal type.

\section{Decay time for the Richmond-Gulf region}

An example of the use of SLIs in GIA is the derivation of the decay time of GIA from selected sea-level diagrams for formerly glaciated regions. In particular, Ångermanland, central Sweden, and Richmond Gulf, southeastern Hudson Bay, display the pronounced RSL-height fall typical of regions near the former glaciation centres. The SLIs from Ångermanland are based on Holocene varves deposited near the mouth of Ångerman River exactly at the contemporaneous mean sealevel height (see Cato, 1998, for an overview of the Ångermanland data). The dating of the varves is carried out by counting them and relating gaps in the stratigraphy to ${ }^{14} \mathrm{C}$ chronology (e. g. Andrén et al., 1999; Wohlfarth and Possnert, 2000).

The data reflecting the RSL-height fall in the Richmond-Gulf region (Figures 4 and 5) are less directly related to the contemporaneous sea-level height and, therefore, discussed more controver- 
sially (e.g. Walcott, 1980; Peltier, 1999; Mitrovica et al., 2000; Fang and Hager, 2002; Mitrovica and Forte, 2004). Following Fang and Hager (2002), we use here the decay time, $T$, and the decay amplitude, $A$, according to the fit of

$$
h_{i}^{\mathrm{P}}=A\left(e^{t_{i} / T}-1\right)
$$

to the SLIs of the Richmond-Gulf region considered. The estimates of $A$ and $T$ proposed so far are listed in Table 1. The differences between the values are essentially due to two reasons: Table 1 the consideration of different subsets of the complete set of SLIs for this region and the use of different methods for the inference of the best-fitting exponential function. Thus, Walcott (1980) used only SLIs based on shells of Mytilus edulis, but included data from Cape Henrietta Maria on the west coast of James Bay. Mitrovica and Peltier (1995) employed the data set provided by Hillaire-Marcel (1980), which is based on SLIs from storm beaches. Peltier (1996) did not provide any details about the data used, but it is reasonable to assume that they are similar to those of Mitrovica and Peltier (1995). In contrast to this, Peltier (1998) considered a new compilation based on a larger number of SLIs from Richmond Gulf and James Bay. Later, Peltier (1999) proposed another estimate of the decay time, now based on the SLIs of Hillaire-Marcel (1980) for Richmond Gulf alone. The estimate of Dyke and Peltier (2000) is based on a subjective fit of an exponential curve to the data. Mitrovica et al. (2000) reviewed the data base used by Peltier (1998), pointed out some errors in the data and proposed a revised estimate for Richmond Gulf only. Fang and Hager (2002) also discussed the data set of Peltier (1998) and estimated a decay time similar to that determined by Mitrovica et al. (2000). Except for Peltier (1998) and Dyke and Peltier (2000), the decay times obtained range from 5 to $8 \mathrm{ka}$ (Table 1).

The new estimate presented here is based on a larger set of 93 SLIs (Table 3, Appendix) provided by Art Dyke (pers. comm.), where 7000 a has been adopted as the upper limit of the calibrated age. Fang and Hager (2002) used a similar limit and justified it by the complex deglaciation history of Hudson Bay. Another argument is that, after 7000 a BP, the eustatic contribution of the 
RSL-height change is negligible in regions covering the former ice-sheet centers (Fleming et al., 1998).

Table 2 lists the membership functions of the SLI types considered. The depositional condition Table 2 of the type shallow water $(\mathrm{SW})$, is represented by trapezoidal membership functions representing the shallow-water habitat of Mytilus edulis. The depositional condition of the type water (W) only provides an upper limit. The corresponding membership function represents the habitat of ordinary shells, potentially sunk driftwood (GSC-27, L-441A, Qu-1291) and a beluga remnant (TO-3713). In contrast to this, SLIs based on driftwood (D) were usually deposited above the mean sea-level height, extending the lower bound to $-2 \mathrm{~m}$. Terrestrial (T) types, such as charred fat or charcoal from forest fires or archeological sites, peat, soil and lake sediments, such as gyttja, are assumed to have formed above the high-tide level ( $>2 \mathrm{~m}$ above the mean sea-level height). Storm beaches along the east coast of Hudson Bay with a proposed 45-a periodicity (HillaireMarcel, 1976) are prominent features and many SLIs related to them have been collected (e.g. Walcott, 1980). Mitrovica et al. (2000) allowed for the resulting offset in the RSL heights by introducing a constant term in Eq. 13. In contrast to this, we consider the fact that shells and driftwood may be related to the storm beaches by extending the upper bound to $6 \mathrm{~m}$ above the contemporaneous RSL height (Allard and Tremblay, 1983).

Figure 6

Figure 6 shows the misfit defined by Eq. 11 as a function of the decay amplitude and decay time. The minimum applies to $(A, T)=(50 \mathrm{~m}, 5.1 \mathrm{ka})$. Clearly visible is the trade-off between decay amplitude and decay time, which is partly responsible for the variability of the previous estimates (Table 1). In Figure 5, the best-fitting exponential function and the range of exponential functions with a misfit $\chi<0.01$ has been added to the data. 


\section{Summary}

We have introduced fuzzy logic for the specification of the depositional conditions of SLIs expressed by suitably defined membership functions. This innovation allows us to consider a larger variety of SLIs in the interpretation of Holocene RSL-height change caused by GIA and to construct sea-level diagrams in an objective and reproducable way. As an application of the method, we have redetermined the decay time for the Richmond-Gulf region using all SLIs available for this region and obtained a value of $5.1 \mathrm{ka}$ and a range of acceptable fits from 4 to 8 ka reflecting the poor quality of the SLIs available from this region.

\section{Acknowledgements}

We thank Carola Tiede and an anonymous reviewer for their constructive comments. We also thank Ludwig Ballani (GeoForschungsZentrum Potsdam), who improved the mathematical formulation of the problem, and Art Dyke (Geological Survey of Canada), who provided the SLIs for the Richmond-Gulf region. The Graphics program GMT (Wessel and Smith, 1991) was employed. This study was supported by the SEAL project, BMBF Project No. SF2000/13.

\section{References}

Allard, M. and Seguin, M. K. (1985), La déglaciation d'une partie du versant hudsonien québécois: bassins des rivières Nastapoca, Sheldrake et à l'Eau Claire, Geogr. Phys. Quat. 39, 13-24.

Allard, M. and Tremblay, G. (1983), La dynamique littorale des îles Manitounuk durant l'Holocène, Z. Geomorphol. suppl. 47, 61-95.

Andrén, T., Björck, J. and Johnsen, S. (1999), Correlation of Swedish glacial warves with the Greenland (GRIP) oxygen isotope record, J. Quat. Sci. 14, 361-371. 
Cato, I. (1998), Ragnar Liden's postglacial varve chronology from the Angermanälven Valley, northern Sweden, Sverig. Geol. Unders. 88, 1-82.

Civanlar, M. R. and Trussell, H. J. (1986), Constructing membership functions using statistical data, Fuzzy Sets Syst. 18, 1-13.

Demicco, R. V. and Klir, G. J. (eds.), Fuzzy Logic in Geology (Elsevier Academic Press, San Diego 2004).

Dyke, A. S. and Peltier, W. R. (2000), Forms, response times and variability of relative sea-level curves, glaciated North America, Geomorph. 32, 315-333.

Fang, M. and Hager, B. F., On the apparent exponential relaxation curves at the central regions of the last Pleistocene ice sheets, In Ice Sheets, Sea Level, and the Dynamic Earth (eds. Mitrovica, J. X. and Vermeersen, B. L. A.) (American Geophysical Union, Washington 2002), pp. 201218.

Filion, L., Saint-Laurent, D., Desponts, M. and Payette, S. (1991), The late Holocene record of aeolian and fire activity in northern Quebéc, Canada, Holocene 1, 201-208.

Fleming, K., Johnston, P., Zwartz, D., Yokohama, Y., Lambeck, K. and Chappell, J. (1998), Refining the eustatic sea-level curve since the Last Glacial Maximum using far- and intermediate-field sites, Earth Planet. Sci. Lett. 163, 327-342.

Harp, E., J. (1976), Dorset settlement patterns in Newfoundland and southeastern Hudson Bay, Mem. Soc. Amer. Arch. 31, 119-138.

Hillaire-Marcel, C. (1976), La déglaciation el le relèvement isostatique sur la côte est de la baie d'Hudson, Cah. Geogr. Quebec 20, 185-220.

Hillaire-Marcel, C., Multiple component postglacial emergence, Eastern Hudson Bay, Canada, In Earth Rheology, Isostasy, and Eustasy (ed. Mörner, N.) (John Whiley and Sons, New York 1980), pp. 215-230.

Klir, G. J., Fuzzy logic: A specialized tutorial, In Fuzzy Logic in Geology (eds. Demicco, R. V. 
and Klir, G. J.) (Elsevier Academic Press, San Diego 2004) pp. 11-61.

Lambeck, K., Smither, C. and Johnston, P. (1998), Sea-level change, glacial rebound and mantle viscosity for northern Europe, Geophys. J. Int. 134, 102-144.

Lee, H. A. (1960), Late glacial and postglacial Hudson Bay sea episode, Science 131, 1609-1611.

Lowdon, J. A. and Blake, W. (1980), Radiocarbon dates XX, Geol. Surv. Can., Paper 80-7, 1-28.

Mitrovica, J. X. and Forte, A. M. (2004), A new inference of mantle viscosity based upon joint inversion of convection and glacial isostatic adjustment data, Earth Planet. Sci. Lett. 225, 177189.

Mitrovica, J. X. and Peltier, W. R. (1995), Constraints on mantle viscosity based upon the inversion of post-glacial uplift data from the Hudson Bay region, Geophys. J. Int. 122, 353-377.

Mitrovica, J. X., Forte, A. M. and Simons, M. (2000), A reappraisal of postglacial decay times from Richmond Gulf and James Bay, Canada, Geophys. J. Int. 142, 783-800.

Peltier, W. R. (1996), Mantle viscosity and ice-age ice sheet topography, Science 273, 1359-1364.

Peltier, W. R. (1998), Postglacial variations in the level of the sea: implications for climate dynamics and solid-earth geophysics, Rev. Geophys. 36, 603-689.

Peltier, W. R. (1999), Global sea level rise and glacial isostatic adjustment, Global Planet. Change $20,93-123$.

Plumet, P. (1974), L'archeologie et le relevement glacio-isostatique de la region de Poste-de-laBaleine, Rev. Geogr. Montreal 28, 443-447.

Stuiver, M. and Reimer, P. J. (1993), Extended ${ }^{14} \mathrm{C}$ data base and revised CALIB $3.0{ }^{14} \mathrm{C}$ age calibration program, Radicarbon 35, 215-230.

Tushingham, A. M. and Peltier, W. R., Relative Sea Level Database, 93-016 (NOAA/NGDC Paleoclimatology Program, Boulder CO 1993).

Vogel, J. C. and Marais, M. (1971. Pretoria radiocarbon dates I, Radicarbon 13, 378-394. 
Volker Klemann,

Walcott, R. I. (1972), Late Quaternary vertical movements in eastern North America: quantitative evidence of glacio-isostatic rebound, Rev. Geophys. Space Phys. 10, 849-884.

Walcott, R. I., Rheological models and observational data of glacio-isostatic rebound, In Earth Rheology, Isostasy, and Eustasy (ed. Mörner, N.-A.) (Wiley, Chichester 1980), pp. 3-10.

Walcott, R. I. and Craig, B. G. (1975), Uplift studies, southeastern Hudson Bay, Geol. Surv. Can., Paper 75-1 Part A, 455-456.

Wessel, P. and Smith, W. H. F. (1991), Free software helps map and display data, EOS, Trans. Am. Geophys. Union 72, 441-446.

Wohlfarth, B. and Possnert, G. (2000), AMS radiocarbon measurements from the Swedish varved clays, Radiocarbon 42, 323-333.

Wolf, D., Klemann, V., Wünsch, J. and Zhang, F.-p. (2006), A reanalysis and reinterpretation of geodetic and geomorphologic evidence of glacial-isostatic uplift in the Churchill region, Hudson Bay, Surv. Geophys. in press.

Zadeh, L. A. (1978), Fuzzy sets as a basis for a theory of possibility, Fuzzy Sets Syst. 1, 3-28. 
Volker Klemann,

Detlef Wolf

\section{Appendix}

[contains Table 3]
Fuzzy logic in analysis of sea-level indicators

Page: 14 of 28 


\section{List of Tables}

1 Estimates of the decay amplitude, $A$, and decay time, $T$, for the Richmond-Gulf region. .

2 Membership functions, $\mu^{\mathrm{E}}(h)$, of SLI types considered for selected heights, $h$. Between the pairs of values indicated, membership functions are linearly interpolated. The relation to storm beaches has been taken into account for the SLI types SW, W and D. . . . . . .

3 Characteristics of SLIs for the Richmond-Gulf region. For each sample are given the laboratory number with the superscript indicating the reference (a: Allard and Seguin (1985), b: Allard and Tremblay (1983), c: Filion et al. (1991), d: Harp (1976), e: HillaireMarcel (1976), f: Lee (1960), g: Lowdon and Blake (1980), h: Plumet (1974), i: Walcott (1972), k: Walcott and Craig (1975)), the conventional ${ }^{14} \mathrm{C}$ age with the standard error (the basin correction is applied to marine samples only if the age is corrected for $\delta^{13} \mathrm{C}$ (e. $\mathrm{g}$. Vogel and Marais, 1971)), the dated material (char fat: charred fat, dl: Delphinapterus leucas, ha: Hiatella arctica, lake sed: lake sediment, me: Mytilus edulis), the SLI type (T: terrestrial, D: driftwood, SW: shallow water, W: water), the observational SLI height, $h^{\mathrm{O}}$, and the $2 \sigma$-calibrated age range with CALIB 4.1 (Stuiver and Reimer, 1993). . . . . . . 


\section{List of Figures}

1 Transformation of the predicted RSL height, $h_{i}^{\mathrm{P}}$, (left) into the fuzzy set, $\mu_{i}^{\mathrm{P}}$, (right) for the prediction of the depositional condition of the SLI considered. The height, $h$, is with respect to present mean sea-level height. . . . . . . . . . . 23

2 Possibility, $p_{i}$, (top) and revised nominal height, $h_{i}^{\mathrm{F}}$, (middle) as functions of the observational RSL height, $h_{i}^{\mathrm{O}}$, according to Eqs. 9 and 10, respectively, (black lines) and the deviation of $h_{i}^{\mathrm{F}}$ from $h_{i}^{\mathrm{O}}$ (black diamonds). Also shown (bottom) is the construction of $p_{i}$ and $h_{i}^{\mathrm{F}}$ for $h_{i}^{\mathrm{O}}=2$ from the intersection, $\mu_{i}^{\mathrm{F}}$, (grey area) of the membership functions of observation, $\mu_{i}^{\mathrm{O}}$, and prediction, $\mu_{i}^{\mathrm{P}} . \ldots \ldots \ldots$

3 Example of the refinement of a fuzzy set defining the depositional condition of a shell living in shallow water, SW, extended by a littoral habitat defined by the mean tidal range (MTR). The fuzzy sets of the SW and MTR depositional conditions are indicated by lines, the union fuzzy set by the hatched area. $\ldots \ldots \ldots \ldots \ldots$

4 Maps showing the locations (circles) of the SLIs of the Richmond-Gulf region (left) and its setting in North America (right). Note that SLI locations may be too close to be distinguishable on the scale of the map. . . . . . . . . . . . . 26

5 Sea-level diagram for the Richmond-Gulf region showing the observational SLI height, $h_{i}^{\mathrm{O}}$, as a function of the calibrated age according to the compilation by Art Dyke (pers. comm.). Lower bounds denote SW- and W-type samples, upper bounds denote D- and T-type samples. The solid line shows the best-fitting exponential function, Eq. 13, with a decay amplitude of $A=50 \mathrm{~m}$ and a decay time of $T=5.1 \mathrm{ka}$. The orange band shows the range of exponential functions with a

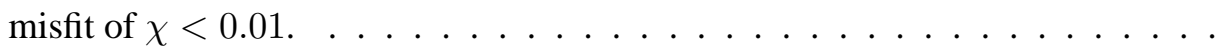


6 Misfit of the exponential function for SLIs from the Richmond-Gulf region as a function of the decay amplitude, $A$, and decay time, $T$. The triangle indicates the best-fitting pair of values obtained in the present study. The estimates and uncertainties found in previous studies are also shown (Table 2). . . . . . . . . 28 


\begin{tabular}{lrl}
\hline Reference & Number of SLIs & $(A, T)(\mathrm{m}, \mathrm{ka})$ \\
\hline Walcott (1980) & 9 & $(-,>5.0)$ \\
Mitrovica and Peltier (1995) & 8 & $(96.2,7.6)$ \\
Peltier (1996) & - & $(-, 7.23 \pm 3.18)$ \\
Peltier (1998) & 48 & $(21.9,3.426)$ \\
Peltier (1999) & 8 & $(53.81,4.68)$ \\
Dyke and Peltier (2000) & - & $(-, 2.0)$ \\
Mitrovica et al. (2000) & 78 & $(-, 5.3 \pm 1.3)$ \\
Fang and Hager (2002) & 48 & $(70.6 \pm 12,6.32 \pm 1.0)$ \\
This study & 93 & $(50,5.1)$ \\
\hline
\end{tabular}

Table 1: Estimates of the decay amplitude, $A$, and decay time, $T$, for the Richmond-Gulf region. 


\begin{tabular}{ll}
\hline SLI type & $\left(h, \mu^{\mathrm{E}}(h)\right)$ \\
\hline SW & $(-50,0) ;(-20,1) ;(6,1) ;(8,0)$ \\
W & $(-\infty, 1) ;(6,1) ;(8,0)$ \\
D & $(-4,0) ;(-2,1) ;(\infty, 1)$ \\
T & $(0,0) ;(2,1) ;(\infty, 1)$ \\
\hline
\end{tabular}

Table 2: Membership functions, $\mu^{\mathrm{E}}(h)$, of SLI types considered for selected heights, $h$. Between the pairs of values indicated, membership functions are linearly interpolated. The relation to storm beaches has been taken into account for the SLI types SW, W and D. 
Table 3: Characteristics of SLIs for the Richmond-Gulf region. For each sample are given the laboratory number with the superscript indicating the reference (a: Allard and Seguin (1985), b: Allard and Tremblay (1983), c: Filion et al. (1991), d: Harp (1976), e: Hillaire-Marcel (1976), f: Lee (1960), g: Lowdon and Blake (1980), h: Plumet (1974), i: Walcott (1972), k: Walcott and Craig (1975)), the conventional ${ }^{14} \mathrm{C}$ age with the standard error (the basin correction is applied to marine samples only if the age is corrected for $\delta^{13}$ C (e.g. Vogel and Marais, 1971)), the dated material (char fat: charred fat, dl: Delphinapterus leucas, ha: Hiatella arctica, lake sed: lake sediment, me: Mytilus edulis), the SLI type (T: terrestrial, D: driftwood, SW: shallow water, W: water), the observational SLI height, $h^{\mathrm{O}}$, and the $2 \sigma$-calibrated age range with CALIB 4.1 (Stuiver and Reimer, 1993).

\begin{tabular}{|c|c|c|c|c|c|}
\hline Lab. no. & $\begin{array}{c}{ }^{14} \mathrm{C} \text { age } \\
\text { (a) }\end{array}$ & $\begin{array}{l}\text { Dated } \\
\text { material }\end{array}$ & $\begin{array}{l}\text { SLI } \\
\text { type }\end{array}$ & $\begin{array}{l}h^{\mathrm{O}} \\
(\mathrm{m})\end{array}$ & $\begin{array}{l}\text { Cal.-age } \\
\text { range (a) }\end{array}$ \\
\hline UL-409 & $6010 \pm 100$ & charcoal & $\mathrm{T}$ & 210 & $6635-7105$ \\
\hline Beta-28576 $6^{\mathrm{f}}$ & $4900 \pm 60$ & charcoal & $\mathrm{T}$ & 210 & $5525-5735$ \\
\hline UL-411 ${ }^{\mathrm{C}}$ & $4880 \pm 90$ & charcoal & $\mathrm{T}$ & 210 & $5430-5825$ \\
\hline Beta-28587 ${ }^{\mathrm{h}}$ & $4520 \pm 80$ & charcoal & $\mathrm{T}$ & 200 & $4880-5380$ \\
\hline $\mathrm{I}-11754^{\mathrm{C}}$ & $3610 \pm 95$ & charcoal & $\mathrm{T}$ & 100 & $3670-4170$ \\
\hline Gif- $1567^{h}$ & $3300 \pm 110$ & charcoal & $\mathrm{T}$ & 62 & $3305-3790$ \\
\hline $\mathrm{I}-10883^{\mathrm{C}}$ & $3040 \pm 215$ & charcoal & $\mathrm{T}$ & 60 & $2765-3665$ \\
\hline $\mathrm{I}-11730^{\mathrm{C}}$ & $2375 \pm 85$ & charcoal & $\mathrm{T}$ & 30 & $2255-2675$ \\
\hline \# & $1050 \pm 50$ & charcoal & $\mathrm{T}$ & 13 & $885-1085$ \\
\hline$G X-2083^{d}$ & $845 \pm 120$ & charcoal & $\mathrm{T}$ & 49 & 590-975 \\
\hline$G X-2065^{d}$ & $795 \pm 160$ & charcoal & $\mathrm{T}$ & 13 & $535-980$ \\
\hline GX-2070 ${ }^{\mathrm{d}}$ & $1130 \pm 95$ & char fat & $\mathrm{T}$ & 17 & $910-1215$ \\
\hline GX-2071 ${ }^{d}$ & $855 \pm 95$ & char fat & $\mathrm{T}$ & 17 & $640-940$ \\
\hline GX-2069 ${ }^{d}$ & $780 \pm 160$ & char fat & $\mathrm{T}$ & 27 & $525-980$ \\
\hline $\mathrm{I}-13406^{\mathrm{a}}$ & $6080 \pm 120$ & peat & $\mathrm{T}$ & 179 & $6710-7210$ \\
\hline $\mathrm{I}-13130^{\mathrm{a}}$ & $5840 \pm 150$ & peat & $\mathrm{T}$ & 170 & $6335-6960$ \\
\hline UQ-622a & $5520 \pm 160$ & peat & $\mathrm{T}$ & 170 & $5980-6590$ \\
\hline $\mathrm{Qu}-140^{\mathrm{a}}$ & $4960 \pm 120$ & peat & $\mathrm{T}$ & 132 & 5435-5945 \\
\hline Lv-698 & $4920 \pm 120$ & peat & $\mathrm{T}$ & 140 & $5425-5895$ \\
\hline GSC-2354" & $4780 \pm 110$ & peat & $\mathrm{T}$ & 110 & $5285-5695$ \\
\hline Qu-142 & $4720 \pm 120$ & peat & $\mathrm{T}$ & 84 & $5075-5675$ \\
\hline GSC-2432 & $4580 \pm 80$ & peat & $\mathrm{T}$ & 90 & $5000-5495$ \\
\hline Lv-797 & $4370 \pm 70$ & peat & $\mathrm{T}$ & 100 & $4810-5105$ \\
\hline $\mathrm{I}-8367^{\mathrm{e}}$ & $2630 \pm 90$ & peat & $\mathrm{T}$ & 38 & $2425-2930$ \\
\hline Qu-1289b & $770 \pm 110$ & peat & $\mathrm{T}$ & 54.7 & $580-875$ \\
\hline GSC-4655 & $5790 \pm 130$ & gyttja & $\mathrm{T}$ & 250 & $6340-6840$ \\
\hline UQ-737 & $2710 \pm 120$ & soil & $\mathrm{T}$ & 81 & $2485-3120$ \\
\hline $\mathrm{Qu}-1297^{\mathrm{b}}$ & $1830 \pm 240$ & lake sed & $\mathrm{T}$ & 50 & $1310-2270$ \\
\hline UPS-2240 & $1560 \pm 100$ & soil & $\mathrm{T}$ & 44 & $1300-1625$ \\
\hline $\mathrm{Qu}-1107^{\mathrm{b}}$ & $720 \pm 80$ & wood & $\mathrm{D}$ & 8.53 & $520-795$ \\
\hline $\mathrm{Qu}-1202^{\mathrm{b}}$ & $720 \pm 80$ & wood & $\mathrm{D}$ & 12.86 & $520-795$ \\
\hline $\mathrm{Qu}-1203^{\mathrm{b}}$ & $680 \pm 80$ & wood & $\mathrm{D}$ & 12.86 & $540-730$ \\
\hline
\end{tabular}


Volker Klemann,

\begin{tabular}{|c|c|c|c|c|c|}
\hline Lab. no. & $\begin{array}{l}{ }^{14} \mathrm{C} \text { age } \\
\text { (a) }\end{array}$ & $\begin{array}{l}\text { Dated } \\
\text { material }\end{array}$ & $\begin{array}{l}\text { SLI } \\
\text { type }\end{array}$ & $\begin{array}{l}h^{\mathrm{O}} \\
(\mathrm{m})\end{array}$ & $\begin{array}{l}\text { Cal.-age } \\
\text { range (a) }\end{array}$ \\
\hline Qu-1204 ${ }^{\mathrm{b}}$ & $570 \pm 90$ & wood & D & 12.86 & $515-645$ \\
\hline GX-2068 & $550 \pm 120$ & wood & D & 27 & $390-700$ \\
\hline Qu-1299 & $480 \pm 90$ & wood & D & 4.4 & $380-585$ \\
\hline Qu-1088 & $410 \pm 80$ & wood & D & 11.76 & $335-535$ \\
\hline $\mathrm{Qu}-1207^{\mathrm{b}}$ & $400 \pm 90$ & wood & D & 8.9 & $305-560$ \\
\hline $\mathrm{Qu}-1205^{\mathrm{b}}$ & $350 \pm 80$ & wood & D & 6.32 & $285-530$ \\
\hline $\mathrm{Qu}-1293^{\mathrm{b}}$ & $330 \pm 100$ & wood & D & 13.5 & $110-545$ \\
\hline $\mathrm{Qu}-1201^{\mathrm{b}}$ & $210 \pm 80$ & wood & D & 9.12 & $0-510$ \\
\hline Qu-1093 ${ }^{b}$ & $190 \pm 90$ & wood & D & 6.2 & $0-515$ \\
\hline $\mathrm{Qu}-1208^{\mathrm{b}}$ & $180 \pm 80$ & wood & D & 6.76 & $0-505$ \\
\hline $\mathrm{Qu}-1209^{\mathrm{b}}$ & $160 \pm 100$ & wood & D & 4.83 & $0-510$ \\
\hline $\mathrm{Qu}-1206^{\mathrm{b}}$ & $150 \pm 80$ & wood & D & 5.45 & $0-480$ \\
\hline $\mathrm{Qu}-1212^{\mathrm{b}}$ & $150 \pm 100$ & wood & D & 10.3 & $0-510$ \\
\hline Qu-1210 & $130 \pm 100$ & wood & D & 9.12 & $0-505$ \\
\hline $\mathrm{Qu}-1090^{\mathrm{b}}$ & $130 \pm 80$ & wood & D & 7 & $0-470$ \\
\hline Qu-1108b & $120 \pm 90$ & wood & D & 7.55 & $0-475$ \\
\hline Qu-1094 & $70 \pm 90$ & wood & D & 6.2 & $0-430$ \\
\hline $\mathrm{Qu}-1095^{\mathrm{b}}$ & $60 \pm 80$ & wood & D & 4.51 & $0-415$ \\
\hline $\mathrm{Qu}-1092^{\mathrm{b}}$ & $40 \pm 80$ & wood & D & 6.2 & $0-310$ \\
\hline Qu-1096 & $20 \pm 80$ & wood & D & 4.51 & $0-305$ \\
\hline GSC- $1287^{i}$ & $6000 \pm 160$ & me & SW & 137 & $6515-7215$ \\
\hline Qu-1294 & $4270 \pm 100$ & ha, me & SW & 65 & $4510-5075$ \\
\hline $\mathrm{Qu}-1290^{\mathrm{b}}$ & $3480 \pm 100$ & me & SW & 52.3 & $3515-3980$ \\
\hline GSC- $2070^{\mathrm{k}}$ & $3360 \pm 60$ & me & SW & 58 & $3435-3735$ \\
\hline Qu-1288 & $2860 \pm 100$ & me & SW & 34.25 & $2780-3235$ \\
\hline GSC- $2348^{\mathrm{k}}$ & $2760 \pm 80$ & me & SW & 44 & $2740-3070$ \\
\hline $\mathrm{Qu}-1296^{\mathrm{b}}$ & $2510 \pm 80$ & me & SW & 32 & $2380-2755$ \\
\hline $\mathrm{Qu}-1097^{\mathrm{b}}$ & $2470 \pm 100$ & me & SW & 31.71 & $2345-2740$ \\
\hline Qu-1099b & $2430 \pm 100$ & me & SW & 28.91 & $2320-2740$ \\
\hline Qu-1295 & $2410 \pm 90$ & me & SW & 31.5 & $2330-2695$ \\
\hline $\mathrm{Qu}-1101^{\mathrm{b}}$ & $2260 \pm 100$ & me & SW & 26.57 & $2010-2480$ \\
\hline $\mathrm{Qu}-1098^{\mathrm{b}}$ & $2230 \pm 100$ & me & SW & 29.94 & $1970-2425$ \\
\hline $\mathrm{Qu}-1103^{\mathrm{b}}$ & $2050 \pm 100$ & me & SW & 21.94 & $1835-2245$ \\
\hline GSC-2129k & $2030 \pm 60$ & me & SW & 29 & $1890-2100$ \\
\hline $\mathrm{Qu}-1100^{\mathrm{b}}$ & $2026 \pm 100$ & me & SW & 27.26 & $1770-2245$ \\
\hline $\mathrm{Qu}-1102^{\mathrm{b}}$ & $2020 \pm 100$ & me & SW & 23.69 & $1750-2245$ \\
\hline GSC- $2074^{\mathrm{k}}$ & $1790 \pm 60$ & me & SW & 22 & $1610-1825$ \\
\hline $\mathrm{Qu}-1104^{\mathrm{b}}$ & $1760 \pm 90$ & me & SW & 20.38 & $1485-1885$ \\
\hline Qu-1087b & $1680 \pm 390$ & me & SW & 21.43 & $845-2460$ \\
\hline Qu-1105 & $1680 \pm 90$ & me & SW & 18.8 & $1400-1775$ \\
\hline $\mathrm{Qu}-1106^{\mathrm{b}}$ & $1490 \pm 90$ & me & SW & 17.26 & $1280-1515$ \\
\hline $\mathrm{Qu}-1298^{\mathrm{b}}$ & $670 \pm 80$ & me & SW & 4.4 & $575-685$ \\
\hline $\mathrm{Qu}-1064^{\mathrm{b}}$ & $890 \pm 100$ & me & SW & 13.31 & $660-960$ \\
\hline Qu-1081 & $580 \pm 70$ & me & SW & 13.21 & $530-610$ \\
\hline Qu-1068b & $490 \pm 80$ & me & SW & 8.89 & $410-585$ \\
\hline GSC- $1725^{\mathrm{i}}$ & $6000 \pm 210$ & ha & W & 153 & $6420-7285$ \\
\hline UQ-863ª & $5200 \pm 300$ & shells & W & 95 & $5315-6605$ \\
\hline GSC $-27^{e}$ & $4740 \pm 110$ & wood & W & 3 & $5200-5695$ \\
\hline
\end{tabular}


Volker Klemann,

\begin{tabular}{|c|c|c|c|c|c|}
\hline Lab. no. & $\begin{array}{l}{ }^{14} \mathrm{C} \text { age } \\
\text { (a) }\end{array}$ & $\begin{array}{l}\text { Dated } \\
\text { material }\end{array}$ & $\begin{array}{l}\text { SLI } \\
\text { type }\end{array}$ & $\begin{array}{l}h^{\mathrm{O}} \\
(\mathrm{m})\end{array}$ & $\begin{array}{l}\text { Cal.-age } \\
\text { range (a) }\end{array}$ \\
\hline Qu-1067 & $4420 \pm 100$ & shells & $\mathrm{W}$ & 6.41 & $4870-5265$ \\
\hline GSC- $1326^{\mathrm{i}}$ & $4070 \pm 140$ & ha & $\mathrm{W}$ & 24 & $4190-4880$ \\
\hline TO-3713 & $4320 \pm 50$ & $\mathrm{dl}$ & W & 11 & $4825-5015$ \\
\hline Qu-1065 & $3460 \pm 90$ & shells & $\mathrm{W}$ & 16.02 & $3505-3920$ \\
\hline Qu-1066 & $3310 \pm 100$ & shells & W & 6.41 & $3365-3755$ \\
\hline Qu-1082 & $3160 \pm 360$ & shells & W & 19.17 & $2635-4250$ \\
\hline $\mathrm{L}-441 \mathrm{~A}^{\mathrm{e}}$ & $3020 \pm 120$ & wood & W & 6 & $2920-3430$ \\
\hline Qu-1083b & $2780 \pm 110$ & shells & W & 15.24 & $2725-3160$ \\
\hline Qu-1086 & $2720 \pm 370$ & shells & W & 6.32 & $1970-3660$ \\
\hline Qu-1085 & $2560 \pm 350$ & shells & W & 10.41 & $1870-3410$ \\
\hline Qu-1292b & $1680 \pm 90$ & shells & W & 8 & $1400-1775$ \\
\hline Qu-1291b & $1590 \pm 90$ & wood & W & 1.5 & $1320-1645$ \\
\hline Qu-1084 & $1360 \pm 230$ & shells & W & 15.24 & $830-1725$ \\
\hline
\end{tabular}



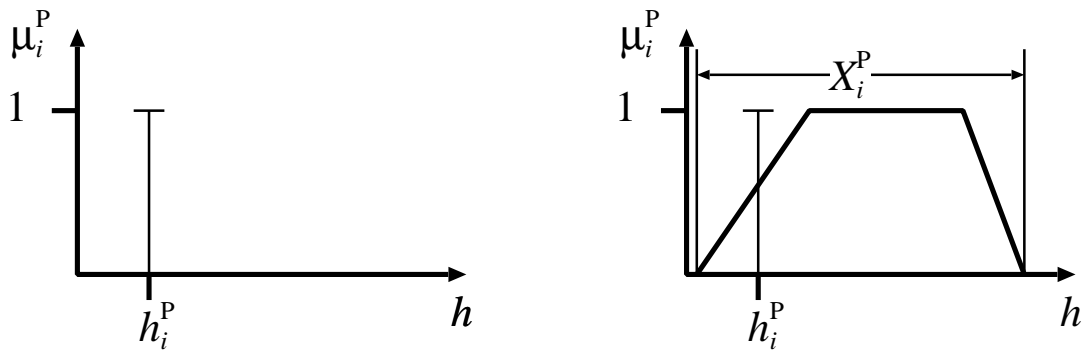

Figure 1: Transformation of the predicted RSL height, $h_{i}^{\mathrm{P}}$, (left) into the fuzzy set, $\mu_{i}^{\mathrm{P}}$, (right) for the prediction of the depositional condition of the SLI considered. The height, $h$, is with respect to present mean sea-level height. 


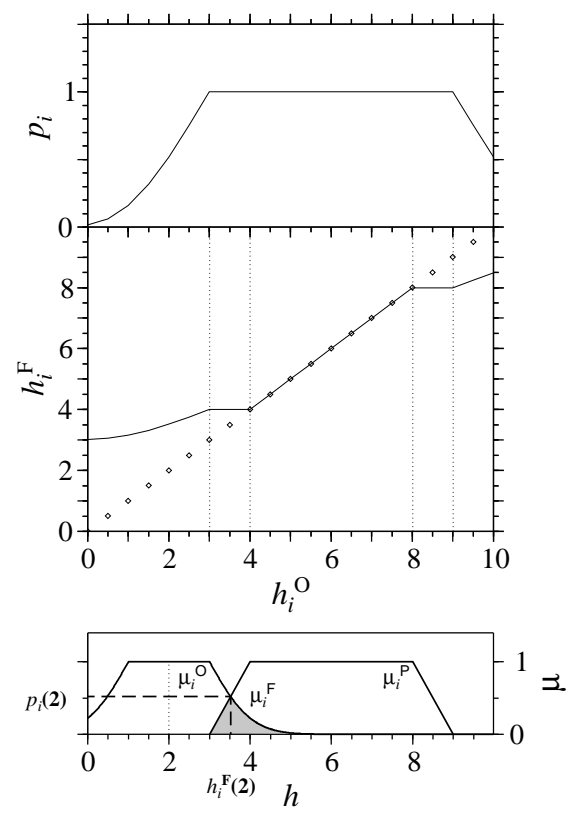

Figure 2: Possibility, $p_{i}$, (top) and revised nominal height, $h_{i}^{\mathrm{F}}$, (middle) as functions of the observational RSL height, $h_{i}^{\mathrm{O}}$, according to Eqs. 9 and 10, respectively, (black lines) and the deviation of $h_{i}^{\mathrm{F}}$ from $h_{i}^{\mathrm{O}}$ (black diamonds). Also shown (bottom) is the construction of $p_{i}$ and $h_{i}^{\mathrm{F}}$ for $h_{i}^{\mathrm{O}}=2$ from the intersection, $\mu_{i}^{\mathrm{F}}$, (grey area) of the membership functions of observation, $\mu_{i}^{\mathrm{O}}$, and prediction, $\mu_{i}^{\mathrm{P}}$. 


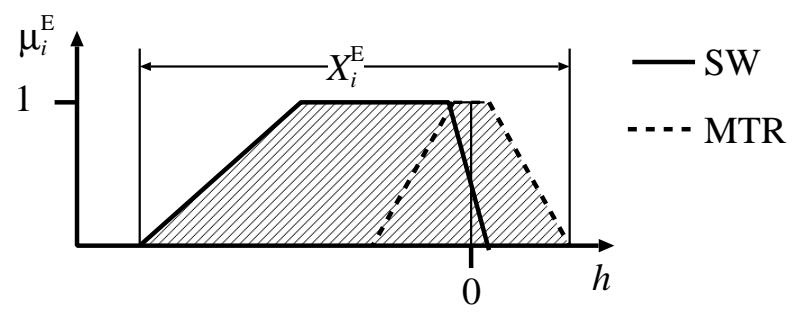

Figure 3: Example of the refinement of a fuzzy set defining the depositional condition of a shell living in shallow water, SW, extended by a littoral habitat defined by the mean tidal range (MTR). The fuzzy sets of the SW and MTR depositional conditions are indicated by lines, the union fuzzy set by the hatched area. 


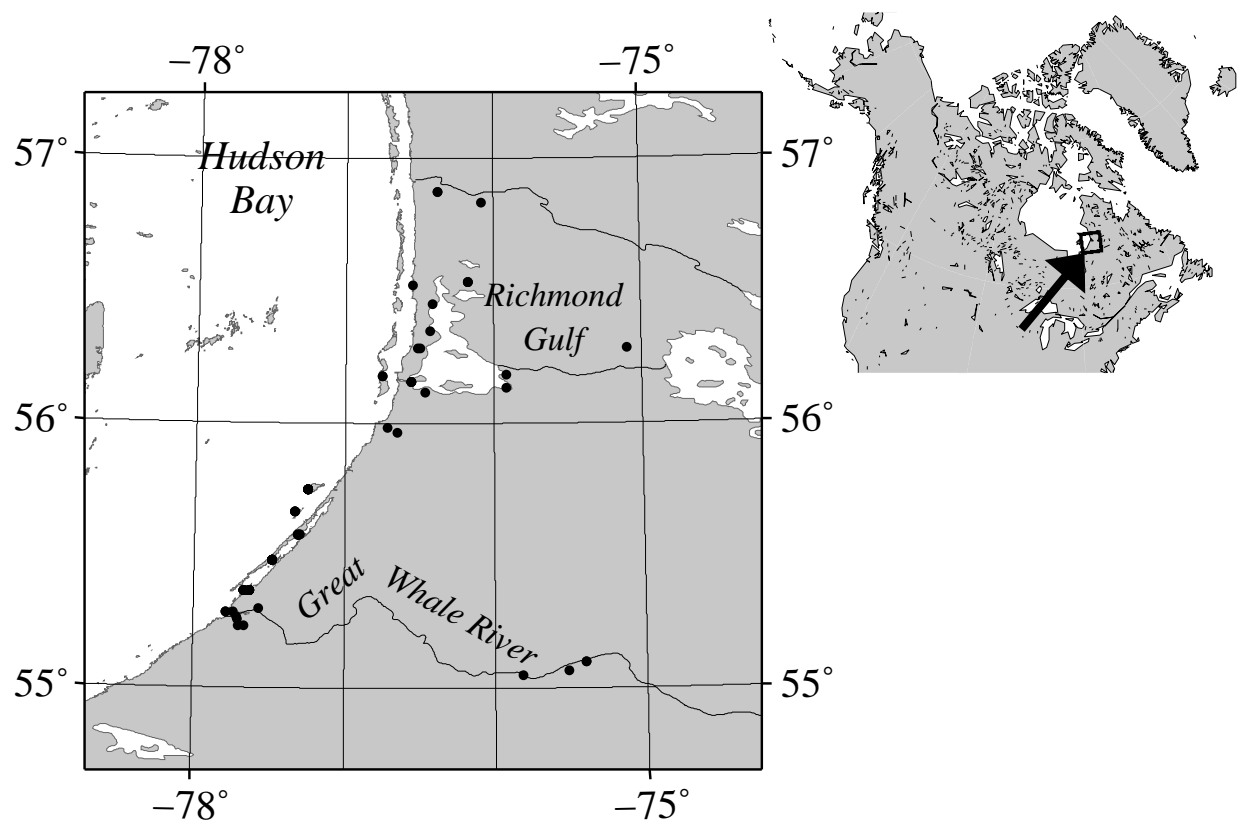

Figure 4: Maps showing the locations (circles) of the SLIs of the Richmond-Gulf region (left) and its setting in North America (right). Note that SLI locations may be too close to be distinguishable on the scale of the map. 


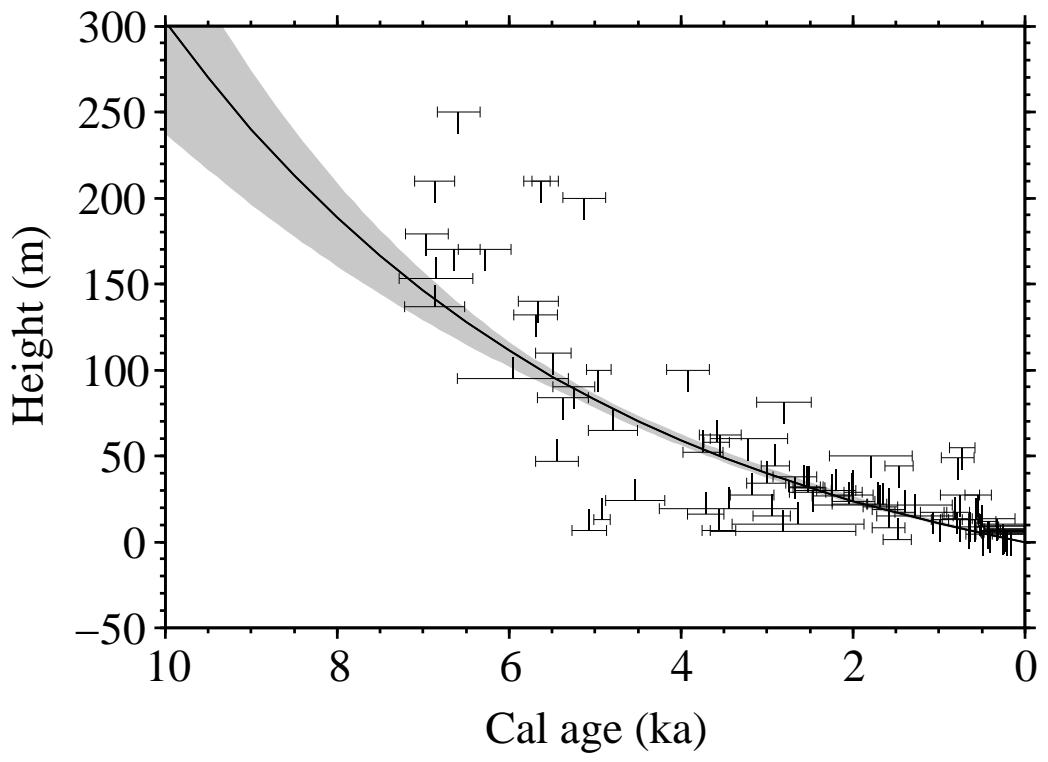

Figure 5: Sea-level diagram for the Richmond-Gulf region showing the observational SLI height, $h_{i}^{\mathrm{O}}$, as a function of the calibrated age according to the compilation by Art Dyke (pers. comm.). Lower bounds denote SW- and W-type samples, upper bounds denote D- and T-type samples. The solid line shows the best-fitting exponential function, Eq. 13, with a decay amplitude of $A=50 \mathrm{~m}$ and a decay time of $T=5.1 \mathrm{ka}$. The orange band shows the range of exponential functions with a misfit of $\chi<0.01$. 


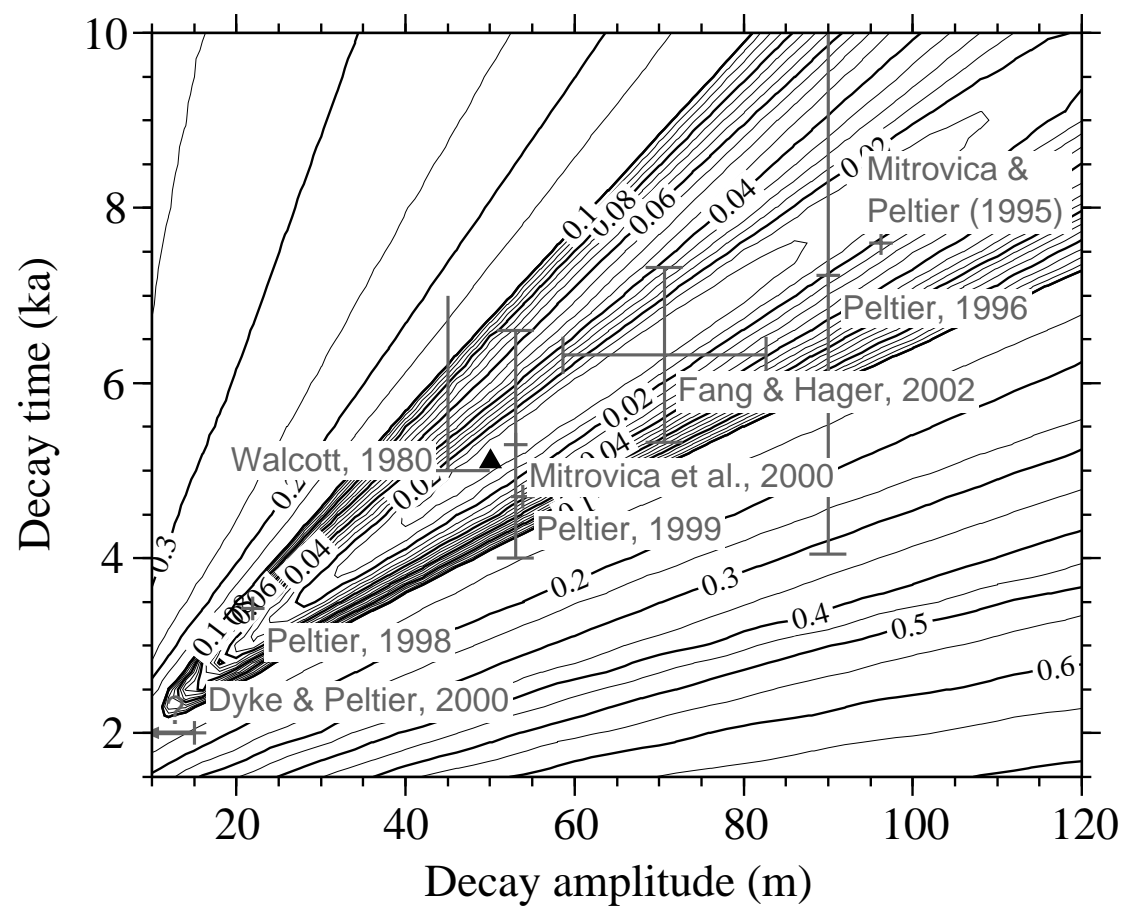

Figure 6: Misfit of the exponential function for SLIs from the Richmond-Gulf region as a function of the decay amplitude, $A$, and decay time, $T$. The triangle indicates the best-fitting pair of values obtained in the present study. The estimates and uncertainties found in previous studies are also shown (Table 2). 